\title{
Lagartija sin cola, de José Donoso (Más ecos de sexo y degradación humanas)*
}

\author{
Reynaldo Bello Guerrieri** $^{* *}$
}

\section{Resumen}

El asunto de este trabajo remite al argumento de Lagartija sin cola, el cual muestra parte de las líneas temáticas desarrolladas por Donoso a lo largo de su extensa obra de mundos cerrados referidos sobre todo al grupo familiar. El objetivo es mostrar que los ecos de la novela excluida, Lagartija sin cola, son registros de angustia, desolación y degradación humanas, que con similar resonancia hallamos en la novelística del autor chileno. El método implicó adoptar una perspectiva multidisciplinaria, basada sobre todo en el análisis (bajo lineamiento humanístico) de los rasgos existentes en el texto. La conclusión a la que se llega demuestra que Donoso, a pesar de las formas empleadas en su trayecto creativo, insistió en contenidos que podemos fijar con facilidad, debido a la obsesiva reiteración de las tramas propuestas.

Palabras clave: argumento, ecos, forma, contenido, protagonistas, temas.

\section{Lagartija sin cola, by José Donoso (More echoes of sex and human degradation)}

\begin{abstract}
The subject of this work refers to the argument of Lagartija sin cola, which mainly shows part of the thematic lines developed by Donoso throughout its extensive closed world work referred to the familiar group. The objective is to show that the echoes of the excluded novel, Lagartija sin cola, are registries of anguish, human desolation and degradation, that with similar resonance, we found in the fiction of the Chilean author. The method implied adopting a multidisciplinary perspective, based mainly on the analysis (under humanistic lineament) of the existing characteristics in the text. The conclusion demonstrates that Donoso, in spite of the forms used in its creative traject, insisted on contents that we can establish with facility, due to the obsessive reiteration of the propose plots.
\end{abstract}

Key words: argument, echoes, form, content, protagonists, plots.

* Este trabajo fue expuesto en el "X Corredor de las Ideas", realizado en la ciudad de Maldonado, Uruguay, el mes de septiembre de 2009.

* Magíster Literatura Latinoamericana Contemporánea. Universidad Metropolitana, Caracas. guebelin@cantv.net 


\section{Introducción}

Una de las obsesiones de la novelística chilena del siglo XX, según el crítico peruano Antonio Cornejo Polar, es expresar el deterioro de las grandes familias: "la corrosión de linajes y personas pertenecientes a un determinado grupo social" (1975:8).

José Donoso, el nombre más conspicuo de los abanderados de esta temática, se apoya justamente en una original manía destructiva cuyo blanco predilecto es el hogar. Con el cúmulo de deshechos heredados, a partir de cercanas y lejanas parentelas, realiza una extensa y perturbadora obra. En ella, el afán del narrador -desde sus primeros cuentos y desde su primera novela, Coronación, hasta la última oficial, El mocho-es aniquilar(se) y negar lo afirmado. Y cuanto afirma y construye con la finalidad de destruir está, como dijimos, en función de la pareja (sin importar el sexo de esta) y de los grupos familiares.

En las originales uniones donosianas, amos y servidores se mezclan en un cúmulo de vivencias y el destino es la destrucción per se. Incluso el narrador -sobre todo el que funge de testigo- suele aniquilarse con la intención de exhibir los escombros vivos que caen de los personajes producto de las situaciones vividas.

La puesta en escena de angustiosos espacios que exponen los secretos horrores del placer, la fiebre de la liberación, la usurpación de identidades y el dominio y caída de la familia burguesa -a la cual Donoso perteneció- son situaciones anómalas que aparecen desde las primitivas líneas de sus relatos y se multiplican en novelas de desmesuras y aberraciones para formar una gran metáfora donde la idea de derrumbe predomina y es la sólida imagen que queda del conjunto de la obra del obcecado narrador.

Basta examinar uno de sus libros (cualquiera) o la totalidad de la obra narrativa del chileno para ver que esta gira en torno a un único tema: el derrumbamiento, la destrucción que arrastra a las familias que creó y a los individuos -con sus pathos y nostalgias- que las integran. La hybris (para los griegos clásicos la maldición humana que se disuelve en la tragedia) está presente en el desolador espacio familiar que se mueve en dos niveles: el real y el ficticio.

Como el mismo Donoso dejó ver en declaraciones, tales familias literarias son reflejo de hechos "vistos" u "oídos": son verdades mentiras o mentiras cuyos orígenes entrañan la realidad con toda su carcomiente y devastadora condena; es decir, con su hybris. 
Esta es, en síntesis, la materia de un novelista que a punta de certezas e inventos interpola secuencias donde el sexo, la degradación humana y el caos, pueblan las casas y algunos espacios abiertos, preferiblemente de las ciudades, que ocupan su vasta e imaginativa obra.

\section{Más ecos de sexo y degradación humanas}

Lagartija sin cola, novela que permaneció oculta durante bastante tiempo, repercutió como noticia en Chile y en el orbe de las letras hispanoamericanas, latinoamericanas e incluso mundiales en 2007, año en el cual los herederos del autor dieron la noticia de la existencia de la singular obra y de una serie de papeles y cartas que daban cuenta de otras facetas en la vida de José Donoso Yánez.

El crítico peruano Julio Ortega informó como "Noticia" que Donoso empezó a escribir Lagartija sin cola en enero de 1973 en el pueblo español de Calaceite, donde había adquirido una casa antigua cuya reparación, según apuntan sus biógrafos, le sería más costosa. En principio, la obra iba a llamarse La cola de la lagartija.

Hoy día el manuscrito se encuentra en el archivo de José Donoso de la Biblioteca de la Universidad de Princeton, Estados Unidos, lugar donde escribió en inglés sus dos primeros cuentos: "The blue woman" (1950) y "The poisoned pastries" (1951) que publica en M.S.S., revista literaria de la que fue fundador y coeditor.

Julio Ortega, quien revisó el original de Lagartija sin cola y dejó establecido el texto final para su posterior publicación, concluye que el chileno decidió renunciar a la revisión de la novela; en lo que a nosotros respecta -es pertinente usar el pluralis concordiae-, la abandonó. Y hasta donde se sabe, nunca dijo por qué ni ha aparecido alguna nota donde se dé cuenta del porqué de su decisión de poner de lado a una de sus criaturas.

Se podría inferir que Donoso la dejó inconclusa. Ello, debido a la sensación de producto no acabado, a pesar de la alta profesionalidad de la escritura presente en la obra. Al respecto, Julio Ortega afirma: "Varias veces discurre aquí la distintiva prosa de Donoso, su liviana nitidez, que reverbera a la luz y la sombra de sus obsesiones" (2008: 7). En cambio para el crítico argentino Luis Harss, si rememoramos lo dicho en Los nuestros, libro publicado a finales de los 60 , la prosa de Donoso resultaba enrevesada, decía que el chileno luchaba con el idioma y ganaba y perdía batallas. 
Lo cierto es que Donoso nunca se deshizo de su "lagartija", o quizás de la cola del saurio. Y es precisamente esa conciencia de salvaguarda, tanto del creador como del crítico peruano Julio Ortega, la causante de que la obra haya podido ver la luz de la publicación treinta y cuatro años después. Pero no solo esa obra estaba entre los papeles legados, también se supo de los esbozos de tres novelas que Donoso no llegó a escribir: Paseo, Piragua y El tigre. Esta última, según informaciones aparecidas en Internet, pretendía ser una novela decididamente gay.

A propósito de tal condición, leamos lo que dice Marcos Ricardo Barnatan en una aguda y grata reseña crítica aparecida en El Mundo de Chile y que lleva el sugerente título de "La doble vida de José Donoso":

Cuando el escritor chileno José Donoso (1924-1996) publicó en 1967 su tercera novela, El lugar sin límites, tocó muy de cerca el tema de la homosexualidad y el travestismo. El mundo es un gran escenario y en él todos interpretamos un papel, pero los actores a veces deciden cambiar de papel y deben recurrir entonces al disfraz, a la interpretación o al uso de la máscara si no quieren asumir públicamente al nuevo personaje. Una obsesiva presencia que, como los mundos cerrados de la vejez y de la infancia, podemos rastrear con facilidad en toda su obra literaria. (2003: 1).

A pesar de las bondades críticas que muestra el artículo de Marcos Ricardo Barnatan, no resulta correcto decir que en El lugar sin límites el tema de la homosexualidad y el travestismo son tocados muy de cerca por Donoso: el tratamiento que el escritor chileno le da a esos asuntos es digno del infierno mayúsculo creado en la obra, comparable en lo esencial a los nueve círculos precisados por Dante en su Comedia. Pero el lugar que se sugiere en la novela de Donoso como inframundo, lo encontramos en la Tierra, en el pueblo que el narrador de la obra designó con ese metafísico nombre. Por lo tanto, el tema de la homosexualidad y el travestismo son tocados a flor de piel, con ganas de llegar hasta la médula, beso de muerte y monstruo de tres cabezas formado por un trío de desvalidos humanos que trastrocan sus burdas existencias.

\section{Temática insistente}

Lagartija sin cola muestra parte de las líneas temáticas desarrolladas por Donoso a lo largo de su extensa literatura; temática que sintetizamos con la palabra degradación, la cual, directamente, involucra lo sexual; 
degradación y sexo, en la mayoría de los casos, remitidos al grupo familiar.

Armando Muñoz-Roa, personaje principal de Lagartija sin cola, es un pintor frustrado y autoexcluido del grupo de los informalistas. Más que un frustrado, se trata de un vanidoso neurótico que nunca creyó ser discípulo de nadie y que vivió persuadido de que era infinitamente original; un artista que basó su desprendimiento del grupo de los informalistas apoyado en un supuesto compromiso con el arte, compromiso que, al leer entre líneas, podríamos catalogar de hipócrita, pues la actitud del pintor, a través de las reflexiones que va soltando, lo muestran enteramente personalista:

Ningún exterior dejó huella en mi pintura. Durante los años que me dediqué a ella quemé toda mi vitalidad en un esfuerzo de la imaginación, de rigor, de cálculo, de emoción frente al problema sumo de la pintura, eliminando de mis lienzos toda sugerencia de objeto y de paisaje. Era una pintura que bien podía haber hecho sin jamás salir de este piso ni conocer otra cosa que las aborrecidas comodidades proporcionadas por Luisa. (2008: 194).

Esa declaración -aunque sea para sí mismo- de autonomía y de querer ser libre en cuanto a su creación artística y su vida, proyecta al pintor Armando Muñoz-Roa como un romántico. ${ }^{1}$

A propósito de pintores, la obra donosiana destaca unos cuantos. En La misteriosa desaparición de la marquesita de Loria está el mediocre Archibaldo Arenas (según lo califica el narrador). En Átomo verde número cinco (la segunda de Las tres novelitas burguesas) hay un aspirante a pintor: Roberto Ferrer. También hay un oscuro pintor en Naturaleza muerta con cachimba, nombre de la última de las Nueve novelas.

Respecto a la envidia, veamos lo que dice el pintor Muñoz-Roa, como sabemos, el personaje principal de Lagartija sin cola:

1 En relación al tema, el crítico Ricardo Ferrada Alarcón puntualiza: "El problema de la autonomía y de la libertad artística, visto puntualmente por Tzvetan Todorov en el capítulo "El lenguaje poético" de su libro Crítica de la Crítica (1991), señala las raíces románticas de ese principio". (2009: 108). En El jardín de al lado pintan, con posturas antagónicas, Pancho Salvatierra y Adriazola. El primero es un triunfador, sus cuadros alcanzan grandes cotizaciones y son expuestos en las principales galerías de arte de París, Zurich, Nueva York, Londres... Como una circunstancia que repite el escritor chileno en otros contextos narrativos, el éxito de Salvatierra le provoca a Adriazola punzadas de envidia. 
Envidia, dijeron, naturalmente, porque el nombre de MuñozRoa es el menos brillante de todo el grupo, el que menos atención ha recibido, cosa que, debo aclararlo inmediatamente, era totalmente inexacta. Envidia. ¿Que me suicidé por envidia? ¿Que me retiré del ruedo, que colgué el hábito, que me castré, en realidad, por envidia, por miedo a la competencia? No lo creo. Luisa sabe que no es verdad. No he sentido envidia por nada ni por nadie en toda mi vida. (2008: 15).

Pensamos que el noble arte de la pintura le sirve a Donoso para enmascarar un sentimiento que ha resultado más afín al no menos noble arte de la escritura.

En un ensayo aparecido en la sección "Cultura y espectáculos" de El Nacional de Caracas y titulado "Literatura y veneno: cuando los escritores destruyen a sus colegas", Claudio Magris dice lo siguiente acerca de los premios y el narcisismo que -y es un secreto a grandes voces- por lo general caracteriza a quien se dedica de lleno o de manera parcial a la escritura:

Los premios literarios, con sus batallas al interior de la rosa de los premiados, procrean odios y bajezas que al compararlas, las pugnas políticas y económicas, incluso las criminales, muestran un espesor más peligroso pero más digno de respeto. La intolerancia del artista -incluso aclamado-, ante las alabanzas que le rinden a un colega suyo, revela cómo el artista está a la par y acaso más que otros, obsesionado por el mecanismo de la competencia y por el temor de que cualquier éxito de un producto de los otros actúe en detrimento de su producto. No por casualidad, los insultos literarios más corrosivos son dirigidos a colegas contemporáneos activos en el mercado del espíritu y el dinero... (2006: B.10).

Lo que dicen Donoso y Magris respecto a la envidia, literatura y veneno, no es una herejía y ni siquiera tales consideraciones representan, en realidad, nada nuevo en el mundillo de islas del archipiélago de las letras, donde el océano que golpea las costas está lleno, desde siempre, de seres rencorosos que usualmente hablan con el estilete en la mano, a manera de arma, con el cual querrían sacar más de un ojo y pinchar más de una mano.

Dejemos de lado a los pintores nombrados que forman parte del intrincado mundo donosiano, y también a la envidia como sentimiento 
de algunas de esas vidas signadas por el arte, la ambición y la creación, y volvamos con el afligido Armando Muñoz-Roa.

Se trata de un hombre que reconoce estar cansado con la vida moderna, que busca un refugio de paz en un sitio donde aún haya cosas que no sean vendibles y por supuesto, que no se hayan deteriorado, o destrozado con la paga sistemática de todo lo que para mal es transformable intentando con cualquier artilugio que adquiera valor. Por sobre todas las cosas, ese hombre busca un lugar donde haya tradición, belleza y una estructura firme a la cual incorporarse sin ser víctima de las hordas movidas por el turismo de corte arrasador.

Por otro lado, ese atribulado ser posee tintes de homosexualidad reprimida. Es un artista egocéntrico, fracasado y envidioso que se cataloga a sí mismo de singular; inclusive, si queremos arriesgar una opinión, de genio. De allí que soltara las amarras de la sociedad y se enclaustrara alejándose prácticamente de todo.

En un momento dado, mediante una analogía, expone su frustración sodomita. Rememora al joven pueblerino Bartolo, quien armado de una sierra eléctrica, corta limpiamente maderos, los maderos que las manos de Armando, deseosas, se negaron a tocar por temor a quedar mutilado.
¿Mostrarme el fino ensamblaje de su cuerpo, más poderoso y distinto al de un hombre o de una mujer por ser tan joven y perfecto, no era una artimaña para indicarme que yo, maduro y sedentario, no tenía derecho a tocarlo? ¿Pero... si yo movía las manos bruscamente -cinco, tres centímetros-y él me las cercenaba? (2008: 214).

Donoso, que en sus obras recurre a dar pinceladas autobiográficas, diría respecto al fracaso de los artistas que son expuestos en sus narraciones, que no es su caso, que no son reflejos de su vida, pues él fue un escritor de notable éxito. En cuanto al sexo y la represión que experimentó el desolado pintor (Armando Muñoz-Roa), es patética la imagen que resume una de las frases que suelta como colofón: "Entre mis piernas, mi bastón cae inerte sobre la alfombra". (215).

Y en otra parte de la novela, prácticamente apartado de la vida, lo escuchamos reflexionar de manera filosófica y hamletiana acerca de lo que fue su inestable paso por el mundo:

¿Lo hice bien? ¿He hecho algo bien en mi vida? Probablemente no. Probablemente lo único bueno que podría hacer sería, pensé entonces, quedarme para siempre mirando el río 
transcurrir en el anochecer, desde esta ventana, en este pueblo perdido en la sierra de Caballa, sin hacer nada para tratar de justificarme, al fin y al cabo la existencia es gratuita, es dada gratuitamente, y también, qué bien lo sabía yo, se puede quitar gratuitamente. Esto, vivir aquí, encerrarse aquí en forma total, prescindir de los placeres más codiciados de la civilización, del trato con amigos de la misma categoría, del cine, de las exposiciones, de las mujeres bellas y sofisticadas, era, de cierta manera, quitarse la vida gratuitamente, una forma de suicidio. ¿No sería llevar hasta sus últimas consecuencias el semisuicidio de haber apostado por la pintura? Si esa apostasía mía de la pintura tenía algún significado más allá del gesto, ¿no debía desaparecer, y no era, entonces, Dors el sitio ideal para desaparecer? (2008: 69).

Sintetizando el argumento de la novela, el pintor Armando MuñozRoa, o Antonio Núñez-Roa, narra la fuga que emprendió de sí mismo (de su arte y del grupo de pintores informalistas del que formó parte) en compañía de Luisa, su prima, amante y benefactora. Al pueblo aragonés de Dors, a donde huyen, llegan como invitados de Armando, la frescamente desenvuelta inglesa Diana, ex esposa del pintor, y los hijos que tuvo con ella.

Diana, cuya abuela había luchado por los derechos femeninos, pertenecía a un mundo liberado y sofisticado y era nieta del escritor Charles Dickens. Lo que la caracterizaba, según el personaje-narrador, es su británico desparpajo y que nunca viajaba sin su chaise longue de seda rococó. Y de extranjerismos que resultan delicados engarces, sobre todo de palabras y frases francesas, inglesas e italianas, está tejida la prosa de Donoso. Quizás donde mayor proyección hace del recurso es en la plástica y atractiva novelita titulada La misteriosa desaparición de la marquesita de Loria.

\section{Civilidad ante todo}

Por tratarse de gente "civilizada" la que deambula por las páginas de Lagartija sin cola, la obra no muestra -al menos en el aspecto familiar- líos relativos a celos. Además, se trata de relaciones pasionalmente gastadas, hermanadas. Lo relevante es que Armando se enamora del empedrado pueblo de Dors e intenta, infructuosamente, rescatarlo del avance de la modernidad. Lo paradójico es que con el tiempo él se reconoce culpable de los cambios que para mal experimenta el vetusto poblado, pues fue 
él, Armando Muñoz-Roa, quien inició el proceso irrevocable de corrupción, ya que ida la tranquilidad que se gozaba en Dors, el pueblo pasó a ser un lugar modernamente modificado por la horda de turistas, que en sucesivas oleadas se propagaron como langostas herbívoras que a su paso destruyen campos de pleno y necesario cultivo.

No solo esos asuntos -huida, turismo mal entendido, soledad- son parte de la temática de Lagartija sin cola. También hallamos en sus páginas, como advertimos, un viejo tema caro a Donoso: la decadencia de la familia, tanto la que creó con su esposa inglesa Diana, como la que en una segunda oportunidad, aunque sin casarse, formó con su prima Luisa y la enajenada y ninfómana hija de esta, Lidia, quien a la larga y de manera natural, como todo lo que ocurre en la novela, termina haciendo el amor con el pintor, por supuesto después de haberlo hecho con una caterva de amantes que incluyen a un guapo y oportunista argentino, y a un agresivo y bigotudo venezolano que tildan de siniestro.

Una de las obsesiones de la novelística chilena del siglo XX, según el crítico peruano Antonio Cornejo Polar, es expresar el deterioro de las grandes familias: "la corrosión de linajes y personas pertenecientes a un determinado grupo social". Y José Donoso, con el psicologismo que caracteriza su narrativa, expone, una vez más, el obsesionante asunto en Lagartija sin cola.

También el escabroso tema de la homosexualidad reprimida, que ya remitimos y que hallamos a lo largo de la novelística del autor, se instala como una enredadera en el cuerpo del pintor Armando Muñoz-Roa, homosexualidad que a ratos da la impresión de querer desprender de sí como si se tratara de la cola de una lagartija, homosexualidad que latía oculta y al parecer carcomiendo la piel del escritor chileno.

A este tenor, las figuras del italiano Bruno y del ya citado español Bartolo, sirven de surtidores que atizan el deseo y resultan inquietantes, seductoras para el desesperado pintor quien, en un momento de afianzamiento de su yo machista va a desear, y de hecho hará el amor, casi sin encontrar objeción -salvo la que él mismo apenas se impuso- con su hijastra Lidia, la hija de su prima y amante Luisa. Sabido es que el incesto, como un cuchillo rozando superficies, está expuesto a lo largo de la narrativa de José Donoso Yánez. El incesto, cuyo representante más conspicuo en la literatura occidental, descansa en la mítica figura del rey Edipo, la gran creación de Sófocles.

Aparte de ser una alegoría sobre el arte y sus consideraciones, ligadas estas en buena medida, y de manera directa e indirecta a las vicisitudes 
de los personajes que pueblan el relato, Lagartija sin cola es, sin el menor asomo de duda, otra obra donde rebotan ecos de la consecuente problemática planteada por Donoso desde sus primeros cuentos y que sintetizamos, como ya dijimos, con cuatro palabras: sexo y degradación humanas.

Podemos establecer una línea conectiva con los hechos que consideramos ecos en la obra donosiana y que, justo por ello, no dejan de estar presentes en la aparentemente abandonada y póstuma novela cuyo manuscrito el escritor chileno, como se sabe, legó -io vendió?-a la Universidad de Princeton.

Lagartija sin cola es importante solo por el hecho de pertenecer a un miembro destacado del llamado Boom latinoamericano, el movimiento literario más resaltante de la región hasta el momento y que tuvo su mayor altura en los 60 del siglo XX, siglo que sirvió para que unos cuantos nombres de las letras de esta parte del mundo se elevaran hasta la cúspide del Olimpo de ese duro y complejo arte. Aunque el movimiento dirigió su alcance hacia la siguiente década, la de los setenta, y tuvo coletazos en la de los ochenta, es la del sesenta, como certifican los críticos, el período que resulta clave en la literatura hispanoamericana del siglo en cuestión. Es sin duda el más descollante y quizás el más rico que ha vivido hasta el presente, aparecen novelas tan importantes como La casa verde, La muerte de Artemio Cruz, La ciudad y los perros, El astillero, Paradiso, Rayuela, Sobre héroes y tumbas, Cien años de soledad, País portátil, por citar algunas.

En efecto, en Lagartija sin cola Donoso continúa sus clásicas obsesiones temáticas, pero esta vez de manera abierta e incluso transparente; mas, sin llegar a ser pedestre en los asuntos tratados. Allí utiliza un personaje narrador en primera persona, a través del cual expone situaciones que tocan (aquí sí con un tenue velo) la referida y angustiante homosexualidad que en vida solapó. Si somos precisos, o justos, deberíamos decir bisexualidad, pues hasta el final de su vida vivió con su esposa e hija. Como sea, su naturaleza gay está expuesta en cartas que por otro lado legó a la Universidad de Iowa.

Se sabe que el crítico y escritor peruano Julio Ortega fue el encargado de revisar la novela excluida, de recuperarla para los lectores. Ahora, aparte de la Introducción que presenta el libro y que Ortega llama "Noticia", desde que la obra apareció, apenas hemos sabido (o tenido noticias) de reseñas y de cortos ensayos aparecidos en Chile. En esos textos no solo se habla de la novela en cuestión, también de las cartas legadas que 
muestran la reservada y agobiante orientación sexual de Donoso, asunto que vislumbramos lo desorientaba.

Para un trabajo de mayor calado que lleva por título José Donoso: sexo y degradación humanas, incorporamos íntegro el análisis que hicimos a las diversas partes del desprendido corpus de Lagartija sin cola. El fin perseguido por el autor de esta propuesta es que la novela consignada en este texto forme parte de una investigación que pretende ser totalizadora, ya que la misma abarca (en muchos momentos tal vez solo para reseñar) toda la obra que se ha publicado del chileno, incluso Poemas de un novelista.

Debido a ello, el estudio de Lagartija sin cola es de sumo interés, pues, como se anunció, encontramos ecos que rebotan en la línea (o líneas) temáticas expuestas por Donoso. Así, con la consecuencia que lo caracteriza, el obcecado narrador expone de nuevo el caro asunto de la comunicación entre seres humanos, y el de sus otras obsesiones que involucran el desamor, el miedo a la vejez, el porqué de la existencia, la envidia entre colegas... y toda esa hybris ligada a la degradación que tiene como punto focal -además de la familia, como ya mencionamos- la mente y el cuerpo de los individuos tratados.

En tal sentido, Donoso es terriblemente moderno, pues la modernidad asumió la plenitud del cuerpo como un lugar de corrupción y pecado. Por tanto, no se trata del cuerpo de la belleza -que Donoso además celebra-, sino el que registra con crudeza lo feo y es envoltorio de excrecencias que hay que expeler. En fin, el cuerpo que la modernidad asume con todos sus orificios y deformaciones es el que aloja y proyecta lo abyecto, que, por supuesto, incluye las enfermedades -a las cuales Donoso fue proclive-, sobre todo las de índole psicológica, no escapan a esa categoría, y la sátira, el viejo género que alguna vez estuvo relacionado con la épica, se convierte en uno de los estilos dominantes de la literatura del siglo XX que subraya, con su ambiciosa presentación de simultaneidad, la alienación, el aislamiento y el dolor del cuerpo torturado. Esto, sin duda, convierte a la literatura moderna -y al arte general de esta épocaen algo tan deprimente.

Cuando apareció por fin la novela en 2007 -había quien estaba a la espera de una nueva obra de Donoso-. Varios artículos electrónicos y blogs de críticos de literatura mostraron reseñas donde se resaltaba sobre todo la aparición del libro; por añadidura, se destacaban aspectos referentes al argumento del mismo, y por curiosidad propagandística se preguntaba (a la vez que se esgrimían respuestas) acerca de las razones 
que tendría Donoso para no ofrecer el manuscrito en 1973 a su casa editorial de entonces, la muy famosa y respetada Seix Barral.

En suma, la obra es reveladora del caos y la destrucción que expuso Donoso a través de su narrativa. De allí que insistamos en que sea fácil relacionarla con la totalidad del corpus narrativo del chileno. No obstante, Lagartija sin cola, como cada obra de Donoso, posee singularidades y las páginas per se arrojan significados propios, los cuales están expuestos a través de un argumento que podríamos catalogar de sencillo.

Como la novela fue gestada en los tempranos 70 (se dice que es de 1973), el autor nombra en párrafos aislados a personalidades emblemáticas y mediáticas de la época: los presidentes norteamericanos Nixon y Johnson; también remite acontecimientos como la Guerra de Vietnam, y nombra como referentes del encumbrado Pop-Rock a estrellas icónicas como Mick Jagger y su grupo (The Rolling Stones) y al famoso cuarteto de Liverpool, The Beatles. Mas, son solo marcos de referencia de la obra que tiene como centro el pueblo de Dors (base de los recuerdos del ofuscado pintor protagonista) y el apartamento de este, su refugio de Barcelona, España, desde donde se proyectan los recuerdos que alimentan el relato.

Lagartija sin cola, insistimos, presenta una temática que el autor nunca traiciona. Luego de la exploración hecha a la novela puede uno compararla con el resto de la narrativa de José Donoso y el resultado es el esperado por el estudioso de lo donosiano: se topará con ecos de situaciones expuestas antes y después de la novela en cuestión.

Como se dijo y es menester reiterar, estas situaciones giran o dan cabida al sexo y a la destrucción que, sobre todo, envuelve al clan familiar, principalmente de la burguesía, pero sin que sea óbice para que las situaciones toquen, de paso, a miembros de familias de la llamada clase baja. Relativo a este tenor, el crítico uruguayo Hugo Achugar observó que la comparación social es asunto recurrente en los narradores donosianos desde sus primeros cuentos y desde su primera novela, Coronación. En efecto, la dialéctica entre amos-servidores que trocan roles la hallamos a lo largo de la totalidad de esas páginas que tienen como corolario la novela El mocho, aun cuando la última que vio la luz de la publicación fue la de 1973, Lagartija sin cola, que re-apareció en 2007.

Lo que a Donoso interesa fundamentalmente de la sociedad para retratar en sus obras son los estados marginales de las personas, no la normalidad de estas en los asuntos cotidianos. Por eso trata la vejez, la infancia, la adolescencia, la locura, la neurosis. Y, debido a su afán por 
lo anárquico, de estas situaciones extremas se derivan otras líneas temáticas como los juegos prohibidos, el incesto, la alienación, la incomunicación, la traición amorosa, los intercambios sexuales, las apariencias, las máscaras, los disfraces, las desapariciones, el homosexualismo, los travestís...

Una vez más se pone de manifiesto la incertidumbre que experimenta la mayoría de personajes del universo donosiano. En esta ocasión, el titubeo, la incertidumbre que brota de la intensa reflexión del pintor informalista Armando Muñoz-Roa: iser la cola de la lagartija o ser la lagartija misma, aunque sin cola?

En cuanto a la conclusión que presenta la novela en general, hay críticos que decantan dos tipos de finales: el del protagonista o héroe (siempre solitario) que se une al resto de hombres y mujeres de su entorno y halla una especie de fraternidad que alude a lo universal, y el que nos muestra un protagonista o héroe "gregario" que simplemente conquista la soledad o esta lo conquista a él.

Sin duda que el último es el caso del pintor Armando Muñoz-Roa.

\section{Conclusión}

Leer cualquier obra publicada por Donoso -o que se haya publicado del autor en cuestión- es experimentar cómo el caos irrumpe en páginas que son constantes y cambiantes metáforas de destrucción, de derrumbamiento familiar y sobre todo de los individuos que integran los determinados grupos sociales que con tanta saña el autor satirizó hasta el fin de sus días. Pero, a la larga, todos esos eventos tiznados de continua degradación, de males que son desenfrenadas hybris, de desmesuras que atraen con su engañosa apariencia, devienen en hechuras estéticas, como es finalmente la aspiración de los grandes novelistas y Donoso, sin duda, es uno de ellos.

El análisis a Lagartija sin cola, o a cualquier obra del chileno, es un proceso que da la impresión de resultar inacabable como inacabable resulta enfrentar obras salpicadas de mixturas, de reiteradas reconciliaciones y contradicciones entre el ser y su entorno, entre lo humano y lo divino, entre lo terrenal y lo metafísico, entre desamparadas parejas fijas o de ocasión; en fin, de un universo múltiple saturado de pasiones descompuestas que buscan a toda costa bañarse en las aguas de la simplicidad, aguas estas generalmente elusivas al autor. 


\section{Bibliografía}

\section{Bibliografía primaria}

Donoso, J. (2008). Lagartija sin cola. Bogotá: Alfaguara.

\section{Bibliografía crítica}

Achugar, H. (1979). Ideologías y estructuras narrativas en José Donoso. Caracas: Celarg.

Barnatan, R. (2003, Septiembre 15). "La doble vida de José Donoso". El Mundo, Santiago de Chile, 1.

Barthes, R. (1973). Ensayos criticos. Barcelona: Seix Barral

Blanchot, M. (1975). El diálogo inconcluso. Caracas: Monte Ávila.

Bravo, V. (1987). Los poderes de la ficción. Caracas: Monte Ávila.

Campbell, J. (1972). El héroe de las mil caras. Psicoanálisis del mito. México: FCE.

Cassirer, E. (1971). Filosofía de las formas simbólicas. México: FCE.

Cornejo, A. (1975). José Donoso. La destrucción de un mundo. Buenos Aires: Fernando García Cambeiro.

Ferrada, R. (2009). El Discurso Crítico de Octavio Paz. Santiago de Chile: Ariadna Ediciones.

Freud, S. (1973). Introducción al narcisismo y otros ensayos. Madrid: Alianza.

Girard, R. (1963). Mentira romántica y verdad novelesca. Caracas: Universidad Central de Venezuela.

Kayser, W. (1964). Lo grotesco. Buenos Aires: Editorial Nova.

Lodge, D. (2002). El arte de la ficción. Barcelona: Península.

Lukács, G. (1975). El alma y las formas / La teoría de la novela. Barcelona: Grijalbo.

Magris, C. (2006, agosto 14). "Literatura y veneno: Cuando los escritores destruyen a sus colegas". El Nacional, Caracas, Cultura y espectáculos, 10 .

Martínez, T. (2008, Febrero 24). “QQué se hizo Luis Harss?” El Nacional, Caracas, 10. 
Praz, M. (1970). La carne, la muerte y el diablo. Caracas: Monte Ávila.

Rank, O. (1976). El doble. Buenos Aires: Orión.

Todorov, T. (1972). Introducción a la literatura fantástica. Buenos Aires: Tiempo Contemporáneo.

_ (1975). Poética. Buenos Aires: Losada.

__ (1989). Teoría del símbolo. Caracas: Monte Ávila.

(1991). Crítica de la crítica. Caracas: Monte Ávila.

Vallejo, A. (1979). Del narcisismo. Buenos Aires: Helguero. 